\title{
Dravidian Language
}

National Cancer Institute

\section{Source}

National Cancer Institute. Dravidian Language. NCI Thesaurus. Code C161909.

A language family spoken mainly in Southern India and parts of Central and Eastern India, as well as in Sri Lanka with small pockets in southwestern Pakistan, southern Afghanistan, Nepal, Bangladesh and Bhutan. 